\title{
A Review of Employee Engagement and Strategies Implementation in Virtual Work Environment
}

\author{
Kumaresh Pal \\ MBA - Marketing \& HR, University School of Business, Chandigarh University, Punjab, India
}

\begin{abstract}
Article Info

Volume 8, Issue 4

Page Number : $114-121$

Publication Issue :

July-August-2021

\section{Article History}

Accepted : 10 July 2021

Published: 15 July2021

This present work report represents the imperative and challenging Human Resource to strategize and maintain a good employee engagement in a virtual work environment. A little empirical and theoretical account of how employees and management can optimize their operational engagement by implementing situation-based strategy in the virtual work environment. It is a review and analysis (quantitative and qualitative) of employee engagement in this virtual world. However, Information Technology and Telecommunication Industry were already on this path of adaptation, but the new normal has made by the COVID-19 pandemic. Due to this situation, a greater shift from a traditional work environment to work from home environment (virtual) has been seen. This paper is an analysis of both work environments and consists of some strategies to implement better employee engagement in this scenario. The paper also includes some secondary data for the analysis between both work environments and followed thematic analysis of data through the Delphi method of survey. The situation was analyzed and strategies are deployed for a better understanding of employee engagement and performance increasing.

Keywords : Employee engagement, Virtual work environment, Employer and employee satisfaction, Psychological empowerment, Employee performance increase, Organizational democracy strategy
\end{abstract}

\section{INTRODUCTION}

The virtual work environment for all corporates and even in education sectors has become the trend due to the Covid-19 pandemic. This new work environment is about focus on the result rather than time. This work environment is only possible because of computer science and globally technological improvement. This situation is not only incorporate sectors but even in Govt. organizations also following the same. This virtual work environment finds the ultimate value of freedom to shift between work and personal life. The virtual work environment also focused on determining work efficiency and costsaving for the organization. Making a proper balance between input (employee afford an organization affords) and output (work done and job satisfaction) is known as employee engagement. Both side contribution should be equal and depends on the particular situation. If we have a look from the base, 
we can see that Human Resources strategies need to consider some facts to reach their ultimate goal. The company's ultimate goal is profit maximization, revenue growth, and cost reduction, to have these all as the result company's HR strategy has to follow three categories in the overall work culture- driven by, delivered by, and valued customer outcomes. First, two categories are focused on employees, the backbone of the company. The company's goal is driven by hiring good employees, extensive training, high pay, and healthy work culture and derived by skilled, committed employees to reach the goal. Therefore, these core competencies generate value for the customer which results in profit, revenue growth, and cost reduction. This whole process can be efficiently managed in a traditional work environment or inside the office environment, but this new normal functional strategy needs some changes to maintain good employee engagement. The virtual work environment has its advantages and disadvantages together. Some advantages in the virtual work environment are lower overhead cost as no office expenses like electricity, rent, internet, meals, etc., and employees are more satisfied due to they can work wherever they want. Some disadvantages of virtual work environment are less cohesiveness (virtual team chooses their working hours), lack of camaraderie (social interactions does help in effective teamwork), securities and compliances issues (confidential and internal data stored in office only where the virtual environment is a huge risky drawback for the company).

\section{Problem statements}

Problems in employee reward virtually- However, inside the office is very simple to track employee performance and rewards them but virtual is a bit of difficult for this.

Lack of training and development- To train employees accordingly in virtual work is very important because of mental health, family pressure but difficult to conduct effectively virtually.

The significant effect after virtual work environmentIt is very clear that with these all advantages and disadvantages of virtual environment needs to make decisions whether it can work for your company or not. However, after this pandemic (covid-19) assembling a virtual work environment and revert to a traditional work environment can be disruptive for your company, because many things need to adapt again for the revert.

\section{OBJECTIVE TO THIS STUDY}

This paper is focused on employee engagement in the virtual environment and key differences from the traditional work environment. The paper will help entrepreneurs to strategize employee engagement policies in the virtual work environment and to figure out key drawbacks and their implementation based on the company culture. Some secondary, quantitative, and qualitative data analysis of this paper will also helpful for all aspiring Human Resource professionals to understand what changes need to adapt as per the company's diversification. Based on the current situation, how to evaluate employee performance and rewards accordingly and to maintain loyalty in the employees is explained in this paper.

\section{LITERATURE REVIEW}

Employee engagement- A literature review Kingstone University, Sandeep Kular, Mark Gatenby, Chris Rees, Emma Soane, Katie Truss. Employee engagement is became a hot topic but now it is about virtual engagement. Employee Engagement: Conceptual Issues- Journal of Organizational Culture, Communication and Conflict; 2006; 10 - The definition of employee engagement whether attitude or behavior. Employee engagement about individual or group. 
The Correlation between Virtual Communication and Employee Engagement- Ryan Nathaniel Mitchell Walden University - Ability to engage virtual employees across various geographic locations \& meet the company and employees both expectation.

Drivers of Employee Engagement in Global Virtual Teams - Australasian Journal of Information Systems Shaik \& Makhecha 2019, Vol 23 - Manage a global virtual team through collaboration and technological adaptation.

\section{RESEARCH METHODOLOGY}

This analysis is based on the key differences between traditional and virtual work environments and the drawbacks. Some secondary data has been collected from a general survey method in those who are working virtually now (employer and employee). Other data has been collected from various websites, focused on human resource operations globally. This research includes how to figure out key differences and implement the drawbacks. All the quantitative and qualitative data were analyzed and implementing strategies were given here. Interpretation and some strategies to implement virtual engagement better have given base on the analyzed data by considering both the work environment.

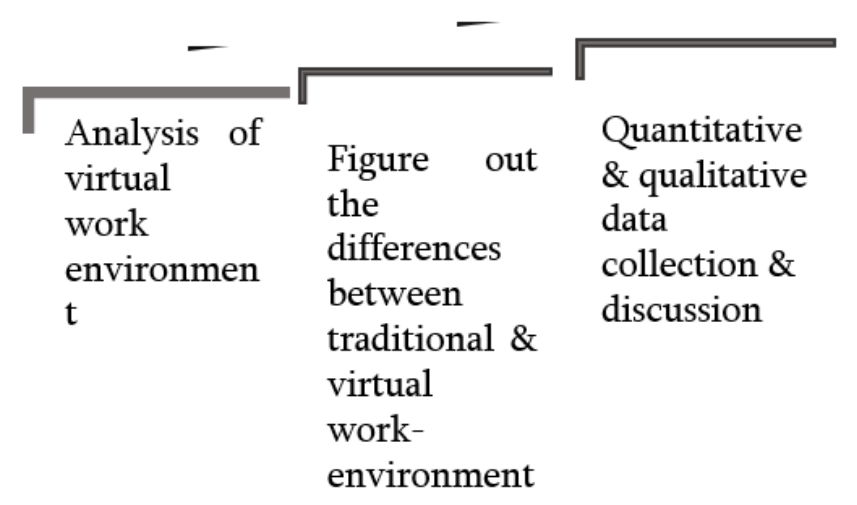

\section{DATA ANALYSIS \& INTERPRETATION}

A set of qualitative data, followed by thematic analysis and Delphi method has collected from several websites and google form surveys. Employee level has segmented below.

Senior level management feedback - Virtual \& Traditional

\begin{tabular}{|l|l|l|l|l|l|}
\hline Designation & Service Year & Country & Continent & Ratings Virtual & $\begin{array}{l}\text { Ratings } \\
\text { Traditional }\end{array}$ \\
\hline General Manager & $5 \mathrm{Yr}$. & India & Asia & $3.8 / 5.0$ & $5.0 / 5.0$ \\
\hline Vice President & $7 \mathrm{Yr}$. & UK & Europe & $4.0 / 5.0$ & $5.0 / 5.0$ \\
\hline Senior Manager & $6 \mathrm{Yr}$. & Australia & Australia & $3.5 / 5.0$ & $5.0 / 5.0$ \\
\hline Associate Director & $6 \mathrm{Yr}$. & Malaysia & Asia & $4.5 / 5.0$ & $5.0 / 5.0$ \\
\hline Deputy Director & $9 \mathrm{Yr}$. & USA & North America & $4.3 / 5.0$ & $5.0 / 5.0$ \\
\hline Assistant GM & $7 \mathrm{Yr}$. & India & Asia & $3.9 / 5.0$ & $5.0 / 5.0$ \\
\hline Senior Director & $10 \mathrm{Yr}$. & USA & North America & $4.0 / 5.0$ & $5.0 / 5.0$ \\
\hline Managing Director & $12 \mathrm{Yr}$. & UK & Europe & $4.5 / 5.0$ & $5.0 / 5.0$ \\
\hline Vice President & $9 \mathrm{Yr}$. & Egypt & Africa & $4.3 / 5.0$ & $5.0 / 5.0$ \\
\hline Deputy Manager & $6 \mathrm{Yr}$. & India & Asia & $4.5 / 5.0$ & $5.0 / 5.0$ \\
\hline
\end{tabular}


Middle level management feedback - Virtual \& Traditional

\begin{tabular}{|l|l|l|l|l|l|}
\hline Designation & Service Year & Country & Continent & Ratings Virtual & Ratings Traditional \\
\hline Manager & 7 Yr. & India & Asia & $4.0 / 5.0$ & $5.0 / 5.0$ \\
\hline Assistant Manager & 9 Yr. & UK & Europe & $4.2 / 5.0$ & $5.0 / 5.0$ \\
\hline Sr. Supervisor & $5 \mathrm{Yr}$. & Australia & Australia & $4.0 / 5.0$ & $5.0 / 5.0$ \\
\hline Sr. Executive & $4 \mathrm{Yr}$. & Malaysia & Asia & $4.5 / 5.0$ & $5.0 / 5.0$ \\
\hline Assistant Manager & $10 \mathrm{Yr}$. & USA & North America & $4.5 / 5.0$ & $5.0 / 5.0$ \\
\hline Supervisor & $9 \mathrm{Yr}$. & India & Asia & $4.2 / 5.0$ & $5.0 / 5.0$ \\
\hline Sr. Analyst & $8 \mathrm{Yr}$. & USA & North America & $4.3 / 5.0$ & $5.0 / 5.0$ \\
\hline Executive Assistant & $12 \mathrm{Yr}$. & UK & Europe & $4.6 / 5.0$ & $5.0 / 5.0$ \\
\hline Sr. Executive & $9 \mathrm{Yr}$. & Egypt & Africa & $4.8 / 5.0$ & $5.0 / 5.0$ \\
\hline Duty Manager & $8 \mathrm{Yr}$. & India & Asia & $4.2 / 5.0$ & $5.0 / 5.0$ \\
\hline
\end{tabular}

Associate/Entry level management feedback- Virtual \& Traditional

\begin{tabular}{|l|l|l|l|l|l|}
\hline Designation & Service Year & Country & Continent & Ratings Virtual & Ratings Traditional \\
\hline Sr. Associate & $7 \mathrm{Yr}$. & India & Asia & 4.7 & $5.0 / 5.0$ \\
\hline Associate & $9 \mathrm{Yr}$. & UK & Europe & $4.0 / 5.1$ & $5.0 / 5.0$ \\
\hline Office Assistant & $5 \mathrm{Yr}$. & Australia & Australia & $4.7 / 5.2$ & $5.0 / 5.0$ \\
\hline $\begin{array}{l}\text { Customer } \\
\text { Assistant }\end{array}$ & $4 \mathrm{Yr}$. & Malaysia & Asia & - & \\
\hline Sr. Sales Agent & $10 \mathrm{Yr}$. & USA & North America & ------- & $5.0 / 5.0$ \\
\hline Admin Associate & $9 \mathrm{Yr}$. & India & Asia & $4.0 / 5.0$ & $5.0 / 5.0$ \\
\hline Salesman & $8 \mathrm{Yr}$. & USA & North America & ------- & $5.0 / 5.0$ \\
\hline Office boy & $12 \mathrm{Yr}$. & UK & Europe & ------- & $5.0 / 5.0$ \\
\hline Service Agent & $9 \mathrm{Yr}$. & Egypt & Africa & ------- & $5.0 / 5.0$ \\
\hline
\end{tabular}

Source- Delphi survey

These data have been collected through a traditional qualitative inquiry in a highly-depth survey across the globe, where we have segmented the employees in three levels of management for any organization- 1 . Seniorlevel, 2. The middle level, 3. Junior level management. We got those all professionals ratings of both work environments for their company. After the feedback of senior-level management, we got an average rating of virtual environment 4.13/5.0, middle-level management 4.33/5.0, and Junior/associate level management gives different feedback, some of them has lost their jobs because of this virtual environment, some of them are partly satisfied and some of them are less satisfied.

Employee segments those have lost jobs during covid-19 pandemic, 2020-2021

We also have listed some professional those are lost their job due this pandemic and virtual work environment. 


\begin{tabular}{|l|l|}
\hline Designation & Sector \\
\hline Parking Attendant & All \\
\hline Cafeteria Attendant & All \\
\hline Door to door salesman & Product based \\
\hline Office boy & All \\
\hline Cashiers & All \\
\hline Bartenders & Hospitality \\
\hline Waiters & Hospitality \\
\hline Expeditors & All \\
\hline Laundry workers & All/Hospitality \\
\hline
\end{tabular}

Source- General Survey

After collection, these data if we analyze we can see that employee satisfaction level is different and based on their job profile such as some are happy and some are lost their jobs. In this situation, maintain good employee engagement and the company's reputation is very different from the traditional work environment. If we see this scenario from a businessperson's side it is somewhere profitable because of cost savings from some positions and loss from another side such as confidential information of the company is in insecure and lack of team management because of the virtual environment.

Here a data set of employee engagement score globally in traditional work environment

\begin{tabular}{|l|r|r|r|r|r|}
\hline \multirow{2}{*}{ Region } & \multicolumn{6}{|l|}{ Employee Engagement Scores of Last five years } \\
\hline & 2015 & 2016 & 2017 & 2018 & 2020 \\
\hline & & & & & \\
\hline Asia Pacific & $65 \%$ & $62 \%$ & $65 \%$ & $65 \%$ & $70 \%$ \\
\hline Latin America & $72 \%$ & $75 \%$ & $75 \%$ & $74 \%$ & $71 \%$ \\
\hline North America & $65 \%$ & $62 \%$ & $60 \%$ & $60 \%$ & $62 \%$ \\
\hline Europe & $60 \%$ & $58 \%$ & $60 \%$ & $60 \%$ & $62 \%$ \\
\hline Africa & $85 \%$ & $60 \%$ & $65 \%$ & $60 \%$ & $60 \%$ \\
\hline
\end{tabular}

Source- Statista.com

\section{DISCUSSION \& RECOMMENDATION}

After analyzing the collected data we can see that employee engagement and employee satisfaction depend on the position of the employee and the company too. In this survey, we found that some employees have lost their jobs because of this virtual environment such as office boy, cafeteria assistant, parking attendant, etc., and some are happy and some are intermediate. Overall it is essential to maintain good employee engagement Employers have a detailed look at several things when working virtually. Because of different geographic 
locations team handling and issues, resolving is a bit difficult for the senior level employee. Here we have given a basic architecture for managing employee virtually with good employee engagement and job satisfaction Virtual employee engagement architecture

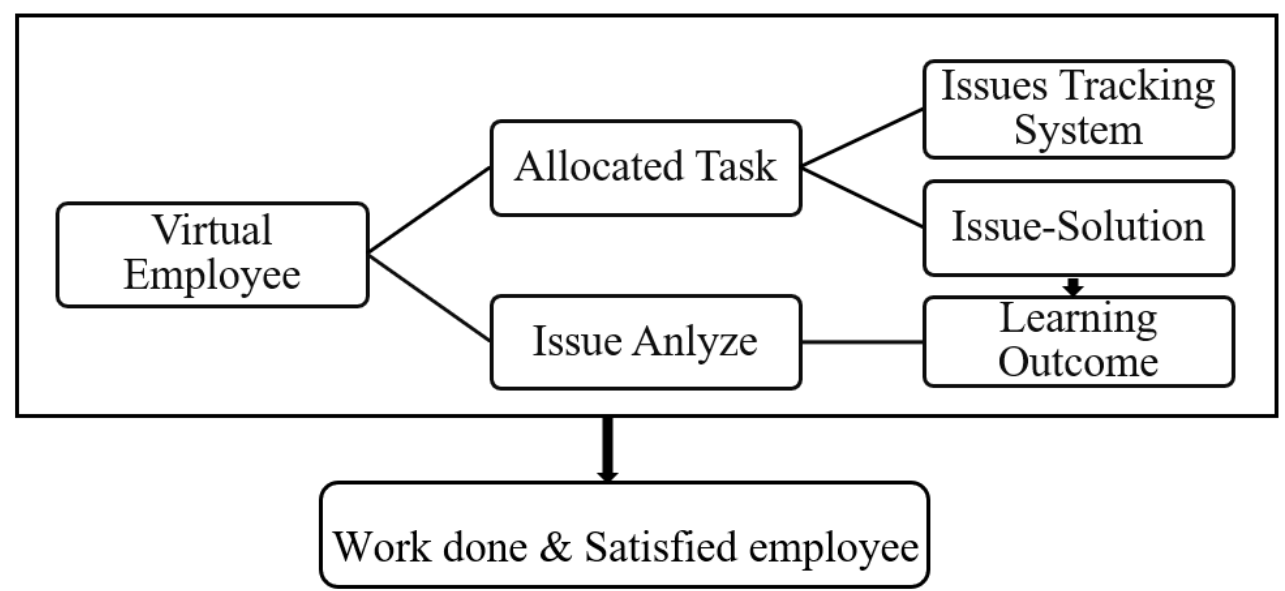

\section{RESULTS AND DISCUSSION}

Recommended human resource strategies for virtual employee satisfaction

Making a balance between high engagement and job satisfaction can improve a virtual work environment with multiple development opportunities.

Working virtually is somewhere complicated for everyone because staying inside the house with family including professional work is complex but we can manage such things to make it better, which is both side responsibility for employee and employer too. Better cooperation can help to have a good engagement. Such things can be considered in the virtual work environment where the company can do cost savings equally.

Employee tracking system-Continuously keep in touch with the team can have a good effect to make work easy. In this tracking system, a manager can include such things as allocated work, issues related to that work, personal issues of employees, finding a solution for those issues, and deep discussion with them.

Virtual loyalty connection- Confidential information of business is a drawback of a virtual work environment. To protect such things manager needs to be conscious every time. Create a transparent teamwork culture to avoid such violence and maintain honesty. Communication at right time is very essential for work and virtually it has become more important. Making a belief that "we are one" and helping each other professionally and personally is essential in this situation.

Virtual accountability count- As a leader, have to maintain a proper accountability count on each team member's work, while it's getting done on time or not if not what are the issues, and try to resolve those issues continuously. It will help to have a better team efficiency virtually.

Leading towards creativity \& innovation- Whether working virtually is time-saving for all, so the company can have a mandate regulation for research and innovation related to work can make a good engagement for everyone.

Provide development opportunities- Flexible work culture has its positive effect, engage your employees on ample development opportunities, in today's digital world we can learn various things related to our profession at home, so increase such awareness will be helpful for better engagement.

Focus on monetary satisfaction- As an employer caring about the monetary satisfaction of employees is beneficial as well as responsibility. Working inside the office is quite easy to identify anyone's dissatisfaction whether virtually is difficult, so have a 
look at monetary satisfaction is beneficial to have employee loyalty and honesty.

Develop foster relationship professionally and personally- Staying connected positively being virtual is a key benefit for good employee engagement and work done by them. Develop a family culture professionally in the virtual work environment that everything can be shareable with each other whether it is professional or personal.

Frequent small rewards- Providing small rewards frequently is beneficial for good engagement, letter of recommendation, small gifts at door, having a small treat on employees birthday/anniversary is not a huge amount for the company but can have a hugely positive effect on work by making them satisfied.

Authentic recognition and promotion- Employer should have a detailed eye on authenticity professionally where they can recognize significant performer and provide promotion on time is essential for goof engagement.

Virtually fun engagement- Organizing some fun engagement on weekend can have a good impact on team building and foster relationships with each other. This can be beneficial for employers and employees too.

Ensure 3600 supportive feedback- Round-the-clock feedback support for each other will be helpful to recognize the weakened or wrong area of work and can rectify on time. So having a time-to-time feedback survey is important for both employer and employee both.

Work flexibility for quality work-life- Quality work life is the most important essential for physical and mental satisfaction for everyone, whether working virtually, flexibility in work possible we can utilize this strategy too.

Focus on quality work rather than long schedule work- Quality over quantity, quality work is far better than a long work schedule, having a remote and flexible work culture to get the things done in time with job satisfaction.
Plan creative corporate social responsibilities- CSR policy is a value generation technique for the company to their customers and employees. Planning cost-friendly CSR policies to implement better employee engagement.

Invest in wellness work- Encourage them for a quality work-life balance by wellness concerning about the company and employees too.

Empower line leader to own employee engagementEmployees don't feel free to always come to a senior manager or directors of the company, so empower them accordingly as line leader for better clear-cut communication among work culture.

Both-way mentorship program- Communication from both sides is very important for better work quality and implementation where it is necessary. Rectify the mistakes of the company, work, or in employees or owner is easy by both way communication timely.

Build empathy to have someone else's position for a day or while if needs- Working virtually and staying in the family can create some moment when having some time for family or any emergency to anyone. Encourage them to do alternatives for each other when it is required.

To have quality employee engagement, an eye on detail is essential. Daily huddles to ensure everyone on the same stage and all are one. Healthy, timely communication to increase business performance and treat employees to become the assets of the company to improve the daily work-life experience. These all strategies will ensure employees' motivation, trust, and being loyal to the company as beneficial for employer and employees too.

\section{CONCLUSION}

Consequently, sensemaking functional strategies for several arrangements in the organization highlight the importance of quality work engagement. Employee engagement indicates motivation and positive energy to employees by their management, work culture. Social bonding among colleagues and continuous tracking of everyone's performance 
through line leader. Coordination among each other and technological adaptation is another key function in the virtual work environment. A good employee engagement in a virtual environment is focused on line leaders to provide empirically grounded recommendations for quality work and quality worklife balance with a continuous issue analyzing among all.

\section{REFERENCES}

[1]. HR from the Outside in: Six Competencies for the Future of Human Resources- Book by Dave Ulrich and Jon Younger.

[2]. Investing in People: Financial Impact of Human Resource Initiatives-Book by John Boudreau and Wayne F. Cascio

[3]. Predictive HR Analytics: Mastering the HR Metric- Book by Kirsten Edwards and Martin R. Edwards

[4]. https://archive.mu.ac.in/myweb_test/M.Com.\% 20Study\%20Material/Human\%20Res.\%20Mana gement\%20-\%20M.\%20Com\%20-\%20I.pdf

[5]. https://assets.kpmg/content/dam/kpmg/pdf/201 6/06/pl-rethinking-human-resources-in-achanging-world.pdf

[6]. https://www.shrm.org/hr-today/trends-andforecasting/special-reports-and-expertviews/Documents/HR-StrategyGlobalization.pdf

[7]. https://www.statista.com/statistics/700031/glob al-employee-engagement-by-region/

[8]. https://www.gallup.com/topic/employee_engag ement.aspx

[9]. https://www.tinypulse.com/blog/17-surprisingstatistics-about-employee-retention

[10]. https://cultureiq.com/blog/company-cultureemployee-engagement-statistics/

[11]. https://www.businessofapps.com/data/linkedinstatistics/

[12]. https://peakon.com/heartbeat/data/employeeengagement/
[13]. Bring Your Human to Work: 10 Surefire Ways to Design - Book by Erica Keswin

[14]. https://store.shrm.org/Predective-HRAnalytics-Mastering-the-HR-Metric

\section{Cite this article as :}

Kumaresh Pal, "A Review of Employee Engagement and Strategies Implementation in Virtual Work Environment", International Journal of Scientific Research in Science, Engineering and Technology (IJSRSET), Online ISSN : 2394-4099, Print ISSN : 2395-1990, Volume 8 Issue 4, pp. 114-121, JulyAugust 2021. Available at doi $\quad$ : https://doi.org/10.32628/IJSRSET218425 Journal URL : https://ijsrset.com/IJSRSET218425 